\title{
Visualization of pig sperm chromosomes by in-vitro penetration of zona-free hamster ova
}

\author{
P. Creighton and J. A. Houghton \\ Department of Microbiology, University College, Galway, Ireland
}

\begin{abstract}
Summary. Zona-free hamster eggs were penetrated by pig spermatozoa capacitated using bovine follicular fluid and Percoll gradients. A mean penetration rate of $80.1 \%$ was obtained from 5 ejaculates from 2 boars. Penetrated eggs were cultured and analysable metaphase chromosome spreads were obtained from $16 \cdot 8 \%$. The analysis of 20 pig sperm complements indicated that 9 were $19, \mathrm{Y}, 10$ were $19, \mathrm{X}$ and 1 appeared to have an XY sex chromosome constitution.
\end{abstract}

\section{Introduction}

Chromosome abnormalities which arise during gamete formation are a cause of mortality and morbidity in all animals and play a significant role in the causation of infertility and fetal loss. It is obviously of fundamental importance that a clear understanding is developed of the causes and consequences of chromosomal error arising during gametogenesis. For this purpose, the direct study of the chromosome constitution of gametes, particularly spermatozoa, would be of considerable advantage. However, until recently this was not possible and all available information on the incidence of chromosomal aberration in gametes was inferred from preimplantation studies and population studies on abortuses, perinatal deaths and livebirths.

During spermatogenesis, the chromosome complement of spermatozoa is packaged in a highly condensed and inert state within the sperm head and is not directly available for cytogenetic analysis. Decondensation occurs only after penetration of an ovum, when factors and mechanisms within the egg cytoplasm decondense the sperm chromatin and allow the male and female pronuclei to prepare for the first cleavage division.

Rudak et al. (1978) described a technique which allowed the direct visualization of human sperm chromosomes for the first time. This method involved the in-vitro penetration of zona pellucida-free ova from superovulated hamsters by capacitated human spermatozoa and the subsequent fixation of the pronuclear chromosomes. Since this initial demonstration, several groups have published data on human sperm chromosomes (Martin et al., 1982; Martin, 1983; Brandiff et al., 1984). Brandiff et al. (1985) found an overall frequency of structural chromosome aberration of $7 \cdot 7 \%$ and an average aneuploidy rate of $1.7 \%$ after the analysis of 2468 sets of human sperm chromosomes.

Zona-free hamster ova have been shown to allow penetration of capacitated spermatozoa from a number of heterologous species including cattle (Hanada \& Nagase, 1981; Bousquet \& Brackett, 1982; Brackett et al., 1982), horse (Brackett et al., 1982) and pig (Imai et al., 1977, 1979, 1980; Hanada \& Nagase, 1981; Pavlok, 1981; Pavlok et al., 1982). However, the methodology for the visualization of human sperm chromosomes has not been extended to any other species. Work in this laboratory on the visualization of bovine sperm chromosomes has been of limited success. However, the method has been successfully extended to the study of the chromosomes of pig spermatozoa. This paper describes, for the first time, the visualization of pig sperm chromosomes.

\section{Materials and Methods}

The modified Krebs-Ringer solution developed by Biggers et al. (1971) called $\mathrm{BWW}$, containing $1 \cdot 71 \mathrm{mM}-\mathrm{CaCl}_{2}$ rather than calcium lactate and $0.5 \%$ bovine serum albumin (BSA, Fraction V, Miles Scientific, Slough, Bucks, U.K.), 
was used as the medium for egg preparation, including dissolution with hyaluronidase and trypsin, sperm preparation and insemination. The $\mathrm{pH}$ was maintained at 7.4 using $20 \mathrm{~mm}$-Hepes (BDH Chemicals Ltd, Poole, Dorset, U.K.) buffer when equilibrated with $5 \% \mathrm{CO}_{2}$ in air at $37^{\circ} \mathrm{C}$.

Adult female golden hamsters were induced to superovulate by intraperitoneal injection of 40 i.u. PMSG (Folligon, Intervet Laboratories Ltd, Cambridge, U.K.) and 50 i.u. hCG (Chorulon, Intervet) $98 \mathrm{~h}$ later. The hamsters were killed, 14-16 h after hCG, by overdose of $\mathrm{CO}_{2}$. The oviducts were dissected out, the ampullary regions punctured and the cumulus extruded. The cumulus mass was digested with $0.1 \%$ hyaluronidase (from ovine testes; Boehringer-Mannheim $\mathrm{GmbH}$, West Germany) for no more than $5 \mathrm{~min}$. The zona pellucida of each egg was removed using $0.1 \%$ trypsin (Sigma Chemical Co. Ltd, Poole, Dorset, U.K. for 1-2 min.

Fresh boar semen was obtained unfrozen in diluent (Boar Diluent I; Merck, Darmstad, West Germany). Samples of 2 ejaculates from a Landrace boar and 3 ejaculates from a Large White boar (Deerpark Pedigree Pigs, Co. Londonderry, Northern Ireland) were studied. Bovine follicular fluid was obtained by aspiration of follicles, $1-2 \mathrm{~cm}$ in diameter, in cow ovaries collected at slaughter. Fluid from several ovaries was pooled and centrifuged twice at $1500 \mathrm{~g}$ for $5 \mathrm{~min}$ to remove blood cells and debris and it was then heat inactivated at $56^{\circ} \mathrm{C}$ for $30 \mathrm{~min}$. Aliquants were stored frozen at $-20^{\circ} \mathrm{C}$ until required.

A sample from each ejaculate was taken, washed twice with Medium BWW by centrifugation at $300 \mathrm{~g}$ and then suspended in $66 \%$ bovine follicular fluid in Medium BWW containing $1 \%$ BSA to give $50 \times 10^{6}$ spermatozoa $/ \mathrm{ml}$ and incubated for $4-6 \mathrm{~h}$ under $5 \% \mathrm{CO}_{2}$ in air at $37^{\circ} \mathrm{C}$. After incubation, the sperm suspension was layered on to a continuous Percoll (Pharmacia AB, Uppsala, Sweden) gradient (Lessley \& Garner, 1983) and centrifuged at $1500 \mathrm{~g}$ for $40 \mathrm{~min}$. A fraction containing $>25 \%$ motile spermatozoa was selected by microscopic examination, washed twice with Medium BWW by centrifugation at $300 \mathrm{~g}$ and diluted to give a final concentration of $25 \times 10^{6}$ spermatozoa/ml. Droplets $(100 \mu 1)$ were constituted under mineral oil in culture dishes ready for the deposition of the eggs. From 5-10 zona-free hamster ova were placed in each droplet and incubated for $3 \mathrm{~h}$ at $37^{\circ} \mathrm{C}$ under $5 \% \mathrm{CO}_{2}$ in air to allow penetration.

After incubation, several ova were removed for microscopic examination to determine whether penetration had occurred. Penetration was detected by the presence of a swollen sperm head or a male pronucleus with tail within the egg cytoplasm (Fig. 1). The penetrated eggs were then transferred to droplets of Ham's Fl0 medium (Gibco Ltd, Paisley, U.K.) supplemented with $20 \%$ fetal calf serum (Gibco) and incubated for $12-14 \mathrm{~h}$ under $5 \% \mathrm{CO}_{2}$ in air at $37^{\circ} \mathrm{C}$. This was followed by transfer into droplets of the same medium containing $0.4 \mu \mathrm{g}$ colcemid $/ \mathrm{ml}$ (Gibco) for a further $4-6 \mathrm{~h}$ for mitotic arrest.

For fixation, the eggs were washed with Medium BWW and placed in a hypotonic solution ( $1 \%$ sodium citrate with $0.01 \%$ polyvinyl alcohol) for $15 \mathrm{~min}$. A droplet of hypotonic solution containing several eggs was then placed on

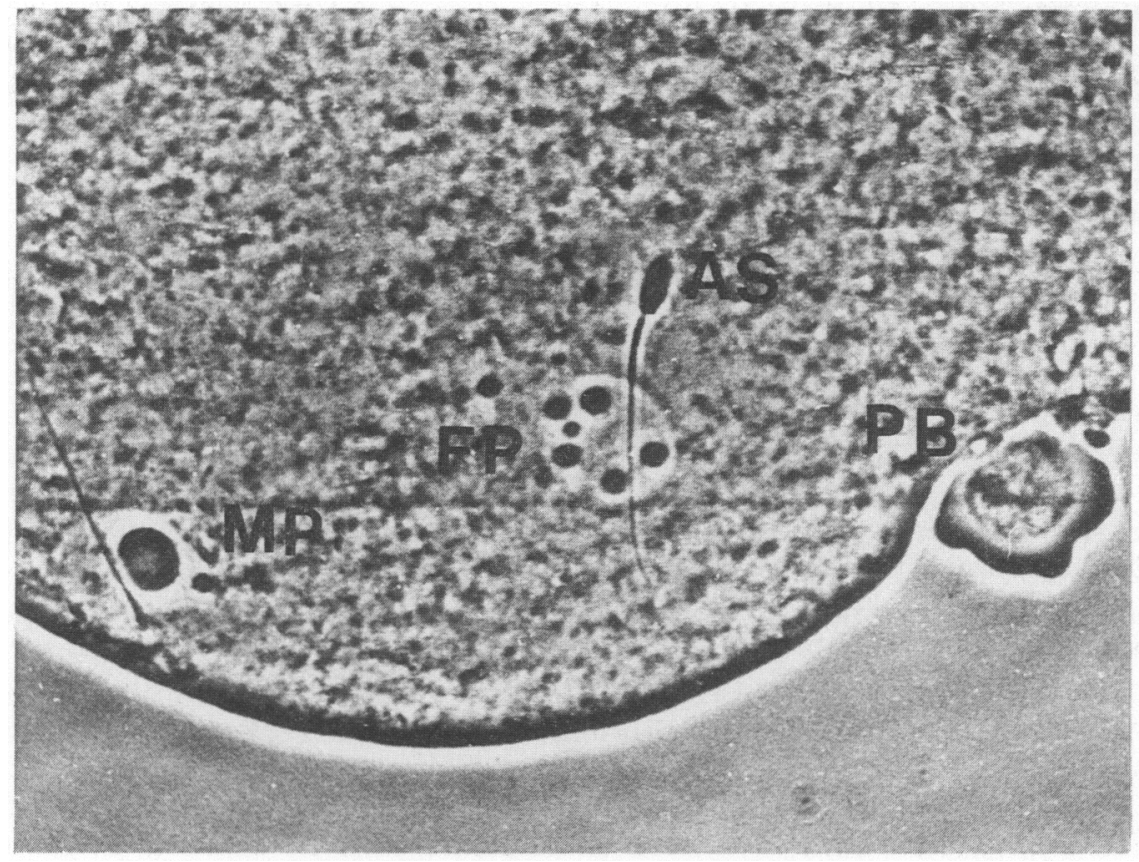

Fig. 1. Zona-free hamster egg showing attached pig spermatozoon (AS), male pronucleus with sperm tail (MP), female pronucleus (FP) and second polar body (PB). 
Table 1. Data from 5 in-vitro penetration experiments with pig spermatozoa and zona-free hamster eggs

\begin{tabular}{|c|c|c|c|c|c|}
\hline & Exp. 1 & Exp. 2 & Exp. 3 & Exp. 4 & Exp. 5 \\
\hline No. of fixed eggs & 67 & 25 & 52 & 43 & 44 \\
\hline No. of hamster/pig hybrid diploids & 56 & 21 & 32 & 37 & 39 \\
\hline Penetration rate $(\%)$ & $83 \cdot 6$ & $84 \cdot 0$ & $61 \cdot 5$ & $86 \cdot 0$ & $88 \cdot 6$ \\
\hline $\begin{array}{l}\text { No. of metaphase chromosome } \\
\text { spreads of analysable quality }\end{array}$ & 7 & 4 & 5 & 6 & 9 \\
\hline $\begin{array}{l}\text { Efficiency of chromosome } \\
\text { preparation as \% of penetrated } \\
\text { eggs }\end{array}$ & $12 \cdot 5$ & 19.0 & 15.6 & $16 \cdot 2$ & $23 \cdot 1$ \\
\hline
\end{tabular}
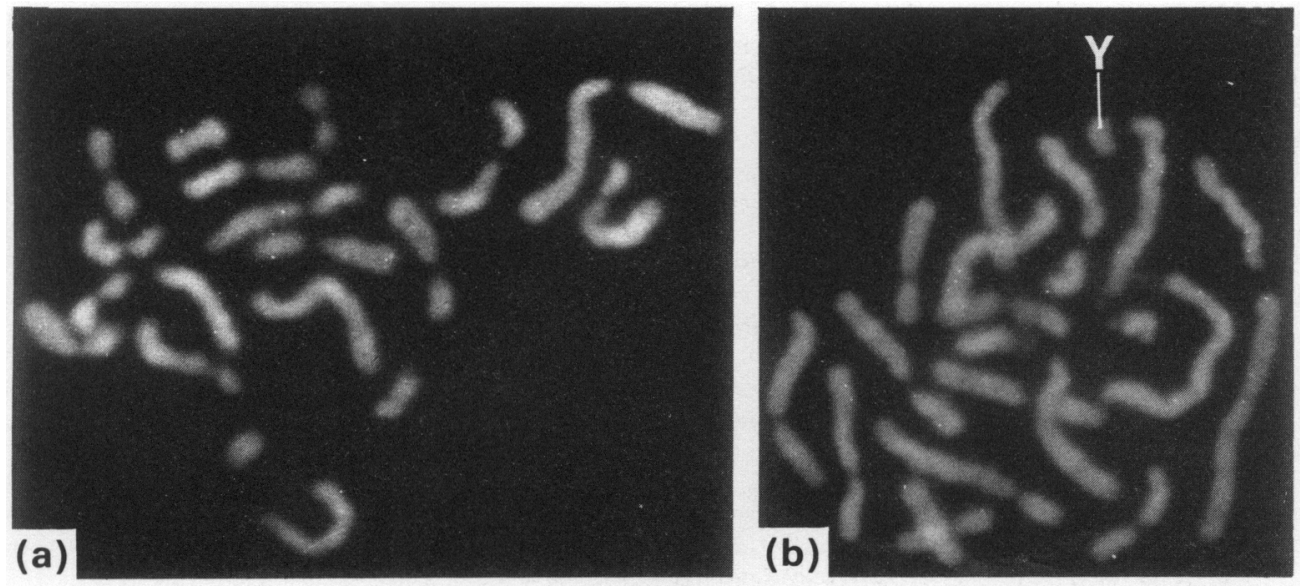

Fig. 2. Pig sperm chromosome preparations: (a) a 19,X sperm chromosome complement; (b) a 19, Y sperm chromosome complement.

a clean slide followed by several droplets of fixative (ethanol:glacial acetic acid; $3: 1 \mathrm{v} / \mathrm{v}$ ) followed by rapid air drying (Tarkowski, 1966). The resulting chromosome preparations were then stained with an atebrin solution, mounted in sucrose (Lichtenberger, 1983) and the partly banded chromosomes were examined with a Nikon Optiphot microscope with $100 / 2$ mercury lamp, BV exciter filter and $480 \mathrm{~nm}$ barrier filter.

\section{Results and Discussion}

Table 1 illustrates results from a series of 5 experiments: Exps 1 and 2 utilized 2 ejaculates from a Landrace boar and Exps 3, 4 and 5 used 3 ejaculates from a Large White boar. The sperm capacitation procedure gave a mean penetration for the 5 samples of $80.1 \%$. This compares favourably with the penetration of zona-free hamster ova by pig spermatozoa capacitated by other methods and with rates obtained from other species including man, horse and cattle (Imai et al., 1977, 1979, 1980; Hanada \& Nagase, 1981; Pavlok, 1981; Pavlok et al., 1982).

The relatively high sperm concentration of $25 \times 10^{6}$ spermatozoa $/ \mathrm{ml} \mathrm{had} \mathrm{little} \mathrm{effect} \mathrm{on} \mathrm{egg}$ viability and eggs were successfully cultured to yield metaphase chromosome preparations of analysable quality. A mean of $16.8 \%$ (Table 1) of penetrated eggs yielded hamster/pig metaphases suitable for karyotyping analysis. Haploid pig sperm and hamster egg chromosome complements 
often remained in two distinct groups after fixation, facilitating chromosome analysis. Identification of chromosomes relied on their morphology and their banding or partial banding pattern. Figure 2 illustrates typical metaphase spreads obtained from pig spermatozoa. Preliminary investigation of 20 pig sperm metaphases indicated that 9 contained a $Y$ chromosome and 10 had an $X$ chromosome: 1 appeared to have an XY sex chromosome constitution.

It is envisaged that, after the analysis of more spermatozoa using this technique, it will be possible to determine the aneuploidy rate in the spermatozoa of normal boars and, by using improved banding techniques, the incidence of structural cytogenetic rearrangements. Results produced by these methods will complement embryological studies of the pig and will lead to a greater understanding of the effects of chromosomal aberration during spermatogenesis on the overall reproductive efficiency of the pig.

\section{References}

Biggers, J.D., Whitten, W.K. \& Whittingham, D.G. (1971) The culture of mouse embryos in vitro. In Methods in Mammalian Embryology, pp. 86-116. Ed. J. C. Daniel. Freeman, San Francisco.

Bousquet, D. \& Brackett, B.G. (1982) Penetration of zonafree hamster ova as a test to assess fertilizing ability of bull sperm after frozen storage. Theriogenology 17, 199-213.

Brackett, B.G., Cofone, M.A., Boice, M.L. \& Bousquet, D. (1982) Use of zona-free hamster ova to assess fertilizing ability of bull and stallion. Gamete Res. $\mathbf{5}$, 217-227.

Brandiff, B., Gordon, L., Ashworth, L., Watchmaker, G., Carrano, A. \& Wyrobek, A. (1984) Chromosomal abnormalities in human sperm: comparisons among four healthy men. Hum. Genet. 66, 193-201.

Brandiff, B., Gordon, L., Ashworth, L., Watchmaker, D., Moore, H., Wyrobek, A.J. \& Carrano, A.V. (1985) Chromosomes of human sperm: variability among normal individuals. Hum. Genet. 70, 18-24.

Hanada, A. \& Nagase, H. (1981) Effects of sperm preincubation in rabbit uterus and imidazol on the penetration of zona-free hamster eggs by bull and boar spermatozoa in vitro. Jap. J. Anim. Reprod. 27, $113-118$.

Imai, H., Niwa, K. \& Iritani, A. (1977) Penetration in vitro of zona-free hamster eggs by ejaculated boar spermatozoa. J. Reprod. Fert. 51, 495-497.

Imai, H., Niwa, K. \& Iritani, A. (1979) Time requirement for the capacitation of boar spermatozoa assessed by their ability to penetrate the zona-free hamster egg. $J$. Reprod. Fert. 56, 489-492.
Imai, H., Niwa, K. \& Iritani, A. (1980) Ultrastructural observations of boar spermatozoa penetrating zonafree hamster eggs. Biol. Reprod. 23, 481-486.

Lessley, B.A. \& Garner, D.L. (1983) Isolation of motile spermatozoa by density gradient centrifugation in Percoll ${ }^{\circledR}$. Gamete Res. 7, 49-61.

Lichtenberger, M.J. (1983) Quick and reversible staining methods for G- and Q-bands of chromosomes. Stain Technol. 58, 185-188.

Martin, R.H. (1983) A detailed method of obtaining preparations of human sperm chromosomes. Cytogenet. Cell Genet. 35, 252-256.

Martin, R.H., Lin, C.C., Balkan, W. \& Burns, K. (1982) Direct chromosome analysis of human spermatozoa: preliminary results from 18 normal men. Am. J. Hum. Genet. 34, 459-468.

Pavlok, A. (1981) Penetration of hamster and pig zonafree eggs by boar ejaculated spermatozoa preincubated in vitro. Int. J. Fert. 26, 101-106.

Pavlok, A., Travnik, P., Kopecny, V. \& Stastna, J. (1982) Fusion of hamster and pig zona-free eggs stimulated by boar and guinea pig sperm at fertilization in vitro. Gamete Res. 6, 189-197.

Rudak, E., Jacobs, P.A. \& Yanagimachi, R. (1978) Direct analysis of the chromosome constitution of human spermatozoa. Nature, Lond. 274, 911-912.

Tarkowski, A.K. (1966) An air drying method for chromosome preparations from mouse eggs. Cytogenetics 5 , 394400 .

Received 8 December 1986 